\title{
REFLEXIONES SOBRE LA VISIBILIZACIÓN DE LO JUVENIL POR LA PRENSA ESCRITA CHILENA, EN CONTEXTO DE PANDEMIA
}

\author{
CAMIla AraYa GUZMÁN ${ }^{1}$ \\ PATRICIA CARRASCO BARREDA ${ }^{2}$ \\ JAVIERA OLIVARES ASTORGA ${ }^{3}$
}

\begin{abstract}
RESUMEN
El presente artículo es un ejercicio reflexivo que busca abordar las formas de visibilización de las y los jóvenes por la prensa escrita digital - como parte de la construcción social de la juventud-, en el contexto de pandemia por el covid-19 en Chile. Se reconoce el contexto adultocéntrico desde el cual se realiza el acto comunicativo, donde predomina una mirada hacia lo juvenil como condición natural sustentada en tres ideas fortalecidas en el contexto de pandemia: la herencia biológica de la definición de juventud, la estigmatización de los grupos juveniles y la lectura al contexto desde un conflicto generacional entre jóvenes y adultos.
\end{abstract}

PALABRAS CLAVE: COVID-19, PANDEMIA, JÓVENES, PRENSA ESCRITA.

1 Magíster en Métodos para la Investigación Social, Universidad Diego Portales. Participante Núcleo de Investigación y Acción en Juventudes, Universidad de Chile. Correo electrónico: carayaguzman@gmail.com

${ }^{2}$ Licenciada en Historia y profesora de Historia y Geografía, Universidad de Chile. Participante Núcleo de Investigación y Acción en Juventudes, Universidad de Chile. Correo electrónico: patricia.carrasco.barreda@gmail.com

3 Trabajadora social, mención en Intervención Socio-Jurídica, Universidad Alberto Hurtado, Chile. Coordinadora académica (I) carrera de Trabajo Social, Universidad Alberto Hurtado. Participante Núcleo de Investigación y Acción en Juventudes, Universidad de Chile. Correo electrónico: javi.olivares.astorga@gmail.com 


\title{
REFLEXÕES SOBRE A VISUALIZAÇÃO DO JUVENIL PELA IMPRENSA ESCRITA CHILENA, NO CONTEXTO DA PANDEMIA
}

\begin{abstract}
RESUMO
O seguinte artigo é um exercício reflexivo que visa abordar as formas de visualização das e dos jovens pela imprensa escrita digital - como parte da construção social da juventude - no contexto da pandemia pela Covid-19 no Chile. É reconhecido o contexto adultocêntrico a partir do qual o ato comunicativo é realizado, onde predomina um olhar para o juvenil como condição natural sustentado em três ideias fortalecida no contexto da pandemia: a herança biológica da definição de juventude, a estigmatização dos grupos juvenis e a leitura ao contexto desde um conflito geracional entre jovens e adultos.
\end{abstract}

PALAVRAS-CHAVE: COVID-19, PANDEMIA, JOVENS, IMPRENSA ESCRITA.

\section{REFLECTIONS ON THE VISIBILITY OF YOUTH-RELATED ISSUES ON CHILEAN WRITTEN MEDIA WITHIN THE CONTEXT OF PANDEMIC}

\begin{abstract}
The present article is a reflection intended to tackle the forms in which male and female young people are made visible by digital written media- as a part of the social construction of youth - within the context of COVID-19 pandemic in Chile. An adultcentric context is recognized as the ground for performing the communicative act based on a perspective of youth as a natural condition supported by three principles reinforced during the contingency of a pandemic: the biological heritage of the definition of youth, the stigmatization of youth groups and the reading of the context from a perspective of generational conflict between young people and adults.
\end{abstract}

KEYWORDS: COVID-19, PANDEMIC, YOUTH, WRITTEN MEDIA. 


\section{INTRODUCCIÓN}

A lo largo de este artículo se comprende lo juvenil como un constructo social, reconociendo la existencia de diversos sectores de la sociedad e instituciones que cumplen el rol de producir discursos y vínculos generacionales, consolidando y validando ciertos imaginarios sobre las juventudes en contextos de sociedades adultocéntricas (Duarte, 2012). De esta manera, podríamos afirmar que ninguna institución ni actor social produce un discurso neutro sobre juventud, sino que llevan implícitos $-\mathrm{o}$ explícitosciertos elementos valorativos que dan cuenta sobre diversas posiciones para comprender la idea de lo juvenil.

Entre los actores que cumplen un rol fundamental en la construcción social de lo juvenil, reconocemos en los medios de comunicación una participación clave, por el ejercicio comunicativo que realizan en un contexto desigual y estratificado en lógicas de dominio adultocéntrico. Para Óscar Aguilera (2014), los medios de comunicación y la prensa elaboran y ofertan un repertorio de imágenes culturales, y una serie de atributos ideológicos y simbólicos sobre la construcción de las juventudes o lo juvenil. Así, la prensa acompaña la construcción sociocultural del sujeto juvenil a través de lo que denomina politicas de visibilidad, al constituir y seleccionar lo que se muestra y lo que no, como una acción desplegada desde una dimensión hegemónica y contrahegemónica, en el marco de un orden social estratificado. Por esa razón, para el autor, analizar las formas de visibilización en el marco comunicacional de la prensa respecto a la idea de juventud permite develar «las formas de nombrar, de asignar atributos socioculturales y determinar roles sociales a los jóvenes» (Aguilera, 2014: 144).

En los actos comunicativos de los medios de prensa existe una cierta tendencia a mostrar la población juvenil como un grupo uniforme, con características transversales más o menos compartidas (Muñoz, 2010). Por lo 
general, los medios de comunicación han contribuido a visualizar a las juventudes desde lo disruptivo - cuando sus acciones poseen una connotación de enfrentamiento o conflicto frente al orden social—, por ejemplo, en relación con la delincuencia, la violencia o el consumo de drogas, fomentando la visión de la juventud como una etapa problemática que mueve la mirada de la juventud como promesa de un futuro, hacia una amenaza del presente (Krauskopf, 2015).

Considerando lo anterior, el texto busca abrir un espacio reflexivo respecto a cómo la prensa escrita-digital ha visibilizado a las y los jóvenes durante el contexto de pandemia en Chile, orientándonos a través de las siguientes preguntas: ¿qué dice la prensa escrita-digital sobre las y los jóvenes en el contexto de pandemia? ¿Sobre qué temas comunica cuando hace alusión a la población juvenil?

\section{DECISIONES METODOLÓGICAS}

El ejercicio reflexivo propuesto se posiciona desde dos supuestos como punto de partida: por un lado, la importancia que ha tenido el uso de lo digital para los actos comunicativos e informativos en este período de confinamiento y, por otro lado, la comprensión de que estos actos se realizan bajo el contexto de sociedades con dominio adultocéntrico.

El desarrollo de este ejercicio ha estado orientado bajo un enfoque metodológico cualitativo de carácter exploratorio, que utiliza como técnica de recolección de información la revisión de prensa y su análisis de contenido, a través de los siguientes pasos.

Primero, utilizamos la aplicación de generación de «Alertas de Google» bajo las etiquetas de: «coronavirus», «covid-19», «pandemia», «jóvenes», «juventud»y «juventudes», desde marzo 2020 hasta mediados de mayo. 
Segundo, diariamente sistematizamos la información que llegaba a modo de alerta con las etiquetas señaladas, en una tabla de Excel, con la siguiente información: «Hitos del coronavirus», «Fecha», «Nombre del medio», «Título», «Nombre de quien (o quienes) habla(n) en la noticia u otro», «Rol (o cargo de quien habla)», «Registro textual de quien habla (o del contenido en sí)» y «Link», tal y como lo demuestra el siguiente ejemplo:

\begin{tabular}{|c|c|c|c|c|c|c|c|}
\hline $\begin{array}{c}\text { Hitos del } \\
\text { coronavirus }\end{array}$ & Fecha & $\begin{array}{c}\text { Nombre } \\
\text { del medio }\end{array}$ & Título & Nombre & Rol o cargo & Registro textual & Link \\
\hline $\begin{array}{l}11 \text { de marzo: } \\
\text { OMS declara } \\
\text { coronavirus } \\
\text { como } \\
\text { pandemia }\end{array}$ & 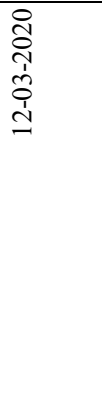 & $\begin{array}{l}\mathrm{La} \\
\text { Tercera }\end{array}$ & $\begin{array}{l}\text { Sin miedo } \\
\text { al riesgo: } \\
\text { jóvenes } \\
\text { aprovechan } \\
\text { ofertas de } \\
\text { vuelos en } \\
\text { medio de } \\
\text { pandemia } \\
\text { por } \\
\text { coronavirus }\end{array}$ & $\begin{array}{l}\text { Miguel } \\
\text { O'Ryan }\end{array}$ & $\begin{array}{l}\text { Médico } \\
\text { pediatra e } \\
\text { infectólogo, e } \\
\text { investigador } \\
\text { del Instituto } \\
\text { de Ciencias } \\
\text { Biomédicas } \\
\text { de la Facultad } \\
\text { de Medicina } \\
\text { de la } \\
\text { Universidad } \\
\text { de Chile }\end{array}$ & $\begin{array}{l}\text { «que lo que uno tiene que } \\
\text { entender en el actual } \\
\text { escenario, es que el } \\
\text { cuidado tiene un gran } \\
\text { aspecto solidario de cuidar } \\
\text { a quienes tienen más } \\
\text { riesgo, que son nuestros } \\
\text { papás y abuelos, y ellos se } \\
\text { infectan de personas } \\
\text { jóvenes que tienen el virus } \\
\text { pero más leve". }\end{array}$ & $\begin{array}{l}\text { https://www.laterc } \\
\text { era.com/que- } \\
\text { pasa/noticia/sin- } \\
\text { miedo-al-riesgo- } \\
\text { jovenes- } \\
\text { aprovechan- } \\
\text { ofertas-de-vuelos- } \\
\text { en-medio-de- } \\
\text { pandemia-por- } \\
\text { coronavirus/QUJI } \\
\text { DNWY2VGJ7EG } \\
\text { VDF52G63XIY/ }\end{array}$ \\
\hline
\end{tabular}

Fuente: Elaboración propia.

Para dicha sistematización, priorizamos la revisión de aquellas noticias, reportajes, crónicas o columnas de opinión, que en su título o bajada de título incorporaran algún concepto vinculante con las clases de edad (niñez, adolescencia, juventud, adultez, adultez mayor - y/o conceptos utilizados como sinónimos-) y estuviesen relacionados con el contexto de pandemia ${ }^{4}$.

Por su parte, es relevante aclarar que en este primer ejercicio de revisión de prensa, no se realizó una comparación sobre las líneas editoriales ${ }^{5}$ y/o los

${ }^{4}$ Algunos medios, en sus plataformas digitales, implementaron una sección especial con noticias y reportajes que se vincularan a la contingencia de pandemia por coronavirus. En esos casos, utilizamos la selección ya realizada por los medios sobre las noticias vinculadas a la pandemia.

5 Aunque comprendemos que las formas de comunicar de la prensa escrita no son homogéneas en este contexto de pandemia — ni en ninguno previo ni posterior-, por 
géneros periodísticos (noticia, crónica, reportaje y opinión), sino más bien lo abordamos como un todo dentro de medios específicos, enfocándonos en qué está diciendo la prensa escrita-digital acerca de las y los jóvenes en contexto de pandemia.

Ahora bien, considerando la gran cantidad de prensa escrita que cuenta con plataformas digitales, utilizamos también el criterio de accesibilidad a las noticias vinculadas a la pandemia, sin necesidad de suscripción ni costo monetario, como por ejemplo La Tercera ${ }^{6}$, El Ciudadano, The Clinic, La Cuarta, El Mostrador, entre otros medios de comunicación. El criterio de accesibilidad a través de plataformas digitales es de gran relevancia, debido a la mayor posibilidad de ser leída en contexto de confinamiento y, por lo tanto, de ser masificada. En consecuencia, se sistematizaron 61 noticias $^{7}$ de distintos medios y no hubo criterio de prioridad según línea editorial en cuanto a la cantidad de noticias sistematizadas, las cuales se distribuyen de la siguiente manera:

el contrario, existen diversos acercamientos hacia lo juvenil, tanto en su producción como reproducción social. Por tanto, se plantea como desafío futuro poder realizar un análisis con mayor profundidad, considerando las diferencias editoriales de los medios de comunicación escritos.

${ }^{6}$ En el caso de La Tercera, por estar en contexto de pandemia, liberó toda la información correspondiente al covid-19.

${ }^{7}$ Ver Anexo 1. 


\section{GRÁFICO 1. DiSTRIBUCIÓN DE LA CANTIDAD DE NOTICIAS REVISADAS Y SISTEMATIZADAS}

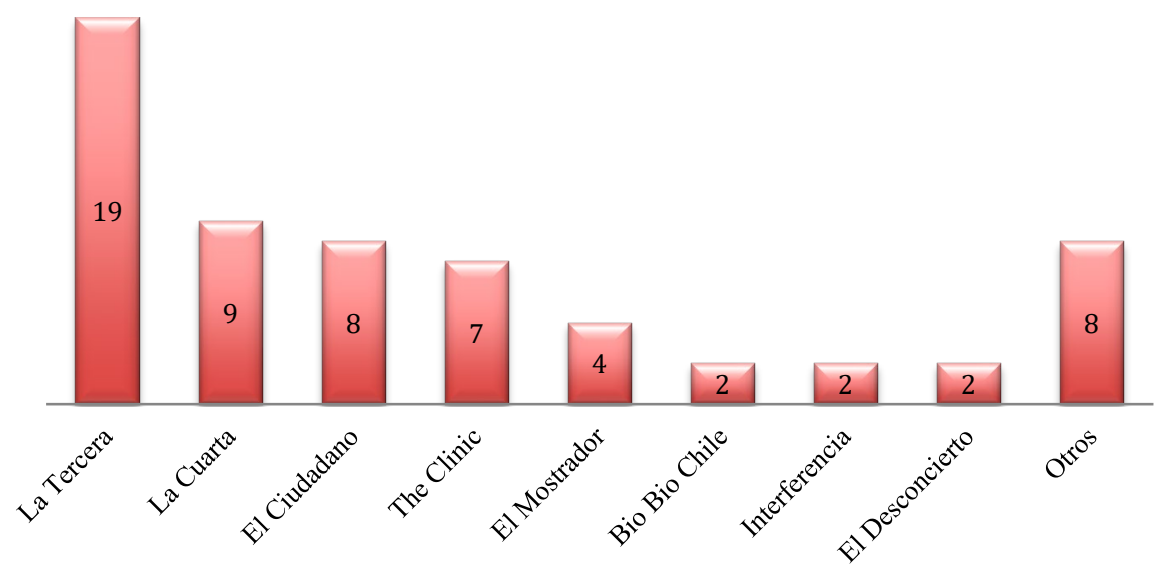

Fuente: Elaboración propia.

\section{JUVENTUDES Y PANDEMIA: ¿QUÉ DICE LA PRENSA ESCRITA-DIGITAL?}

Bajo el supuesto de que el acto comunicativo realizado por la prensa se enmarca en un contexto de sociedades adultocéntricas, que imponen la noción de lo adulto o aquello que alude a la adultez como punto de referencia para los otros grupos etarios (Duarte, 2012), buscamos analizar qué nos dice sobre las juventudes chilenas en contexto de pandemia.

Hace un tiempo ya en Chile, la prensa escrita y los medios de comunicación en general han reconocido el rol de las actorías juveniles en el desarrollo de movimientos sociales, como la «Revolución Pingüina» del 2006 o el movimiento estudiantil del 2011, visualizando a las y los jóvenes en su actuar político, poniendo en tensión el imaginario que aludía al desinterés de las juventudes con la política y lo político, presentado como sujeto apático y anómico (Bustos, 1997; Candía, 2004; Alvear y Miranda, 2006; Fuentes, 2006; Urbano, Rosas y Mundaca, 2006; Baeza y Sandoval 2009; Aguilera, 2009; Torres, 2010). En muchas ocasiones, esa visualización se hizo desde el 
cuestionamiento y desvalorización del actuar político de las y los jóvenes en tanto su condición juvenil, un ejemplo de ello se refleja en el titular del diario Las Últimas Noticias del 3 de junio del 2006: «Cabros, no se suban por el chorro», en un contexto de alto cuestionamiento por parte del mundo adulto hacia las formas de organización de jóvenes secundarios y secundarias, que desde ese entonces se movilizaban contra las lógicas neoliberales del sistema educativo.

Esta tensión también se visualizó en el contexto de revuelta popular del 18 de octubre (18-O) del año 2019, donde se reconoció la importancia de las acciones políticas de las juventudes secundarias en las manifestaciones a nivel nacional, que cuestionaban la cruda desigualdad social como consecuencia de la implementación del neoliberalismo extremo en Chile (Scherman et al., 2020). En este contexto que podemos visualizar como previo a la pandemia, la prensa dio a conocer algunas manifestaciones que aludían a la palabra juventud bajo una connotación "positiva» $\mathrm{y}$ «heroica» por parte de sectores adultos jubilados, quienes manifestaban su agradecimiento a través de pancartas con mensajes como: «Gracias valiente juventud» (Kokaly, 21 de enero, 2020), sostenido bajo un sentimiento de «gran orgullo de tener esta juventud tan decidida a luchar contra las injusticias» (García, en El Mostrador, 18 de enero, 2020). Sin embargo, esta mirada coexistía con discursos de prensa orientados a la criminalización de la protesta, por medio del cuestionamiento al actuar político de sectores juveniles, vinculándolos con la violencia.

Actualmente estamos viviendo una pandemia mundial a causa de la propagación del covid-19, enfermedad que comienza a desarrollarse a fines del 2019 en China. En Chile, el primer caso confirmado fue el 3 de marzo, con el retorno a la ciudad de Talca de un médico que había contraído la enfermedad en un viaje por el Sudeste Asiático. Desde entonces comenzó a aparecer en la prensa escrita chilena, una idea que ya en Europa estaba más o menos consolidada: la enfermedad es más mortal en la población adulta mayor, pero la 
mayor posibilidad de propagación y contagio estaría focalizada en la población juvenil. Así lo representó el 19 de marzo La Tercera, en su editorial de Qué Pasa, con el titular: «Jóvenes serían el principal foco de infección del coronavirus en Chile y el mundo» (Parra, 19 de marzo, 2020). A partir de este supuesto se van destacando dos ideas: por un lado, la mirada biológica con la utilización de la edad como categoría predominante que define a la población juvenil y, por otro lado, otorga atribuciones a sus formas de relacionarse, catalogándolos de «más sociables» que el resto de la población, lo cual fomenta estigmatizaciones sobre las y los jóvenes.

Días antes, La Tercera publicó una noticia con un titular en referencia a las y los jóvenes, reflejando el ideario del joven audaz, sin miedo e irresponsable: «Sin miedo al riesgo: jóvenes aprovechan ofertas de vuelos en medio de pandemia por coronavirus» (Sepúlveda, 12 de marzo, 2020). En su contenido, se alude a la irresponsabilidad de jóvenes que aprovechan descuentos de las aerolíneas para comprar boletos de viaje en el contexto de pandemia, señalando que en este grupo existe la sensación de que son inmunes al virus. Miguel O’Ryan, especialista de la Universidad de Chile, plantea, interpelando a los «valientes viajeros»:

(...) lo que uno tiene que entender en el actual escenario, es que el cuidado tiene un gran aspecto solidario de cuidar a quienes tienen más riesgo, que son nuestros papás y abuelos y ellos se infectan de personas jóvenes que tienen el virus, pero más leve. (O’Ryan, en Sepúlveda, 12 de marzo, 2020)

Algunos medios de prensa escrita dan a conocer el comunicado elaborado por la Organización Mundial de la Salud (OMS), dirigido a las y los jóvenes, como una señal de alerta de que no son invencibles (EFE, 18 de marzo, 2020; Europa Press, 20 de marzo, 2020). De esta manera, paulatinamente se va configurando y transversalizando un llamado a la juventud, a respetar las 
diferentes medidas de confinamiento decretadas en los distintos países del mundo. Se puede interpretar este llamado como una responsabilización hacia la juventud - de manera generalizada y homogeneizada, tanto a nivel mundial como nacional - para no propagar la enfermedad ni aumentar los índices de contagio, bajo el presupuesto de que poseen una percepción de inmunidad ante el covid-19.

En este sentido, la prensa escrita alude a la irresponsabilidad de las y los jóvenes, afirmando que son quienes mayormente han incumplido las normas sanitarias acordes al contexto de confinamiento y cuarentena, que restringen la movilidad social: son quienes rompen los toque de queda (Leppe, 16 de abril, 2020), realizan fiestas aglomerando gran cantidad de gente (LVDM, 3 de mayo, 2020) y ponen en riesgo al resto de la población, sobre todo a adultos mayores.

Paralelo a estos mensajes de responsabilización hacia la población juvenil, la prensa escrita también da cuenta de la tensión generada en el ámbito educacional con la suspensión de clases a mediados de marzo - considerando lo educacional como un aspecto importante dentro de la experiencia cotidiana de las y los jóvenes-. Por un lado, los gobiernos locales a lo largo del país fueron los primeros sectores que, tomando en cuenta las condiciones dentro de las escuelas del sector municipal, demandaron la suspensión de clases para prevenir situaciones de contagio y propagación de la enfermedad (Delgado, 15 de marzo, 2020); sin embargo, por otro lado, el ministro de Educación, Raúl Figueroa, justifica la necesidad de retornar las clases a fines de abril, afirmando que niños y niñas que se contagian no corren mayor riesgo:

Ustedes saben que el coronavirus afecta en mucho menor medida a los niños y jóvenes. Se contagian, pero tienen una tasa de incidencia mucho menor y los que se contagian no corren mayor riesgo en términos vitales. Los papás sienten que volver a clases significa poner en extremo riesgo a los niños y sabemos que eso no es así, porque los niños no son 
un factor de riesgo determinado en esta pandemia. (Ceballos, 23 de abril, 2020).

Así, podemos ver cómo coexisten en la prensa distintas formas de referirse sobre las y los jóvenes en contexto de pandemia. Mientras algunas noticias los vinculan con actos de irresponsabilidad, argumentando que fomentan la propagación en la transmisión del virus, a la vez, se comunica sin mayor cuestionamiento el mensaje del ministro de Educación, que señala que niños/as y jóvenes no son un factor de riesgo, llamándolos a tener una actitud de colaboración «como corresponde».

Hemos podido observar que la imagen de las y los jóvenes por parte de la prensa escrita en este contexto de pandemia tiende a vincularlos con actos de irresponsabilidad, donde actuarían «sin temor» y «sin medir las consecuencias». Esto podría ejemplificarse en la compra de boletos de viajes, o la afirmación de que las personas jóvenes son más sociables $\mathrm{y}$, por ende, tienen mayor contacto con la gente y más altas probabilidades de ser un medio de contagio - bajo el presupuesto de que la percepción juvenil frente al riesgo es naturalmente menor, por lo que hay una tendencia que los lleva a actuar sin medir las consecuencias.

Respecto de la percepción de riesgo de la población juvenil en el contexto de crisis sanitaria, el Ministerio de Desarrollo Social y Familia (MDSF), mediante su Secretaría de Niñez, elaboró una encuesta a adolescentes entre 14 y 24 años de edad, «para saber sus sentimientos y comportamiento frente a la pandemia COVID-19» (MDSF, 28 de abril, 2020). Algunos resultados indican que: el 98\% de las y los jóvenes encuestados/as está muy o totalmente de acuerdo con que la crisis es grave, no obstante, el 40\% considera que adultos exageran sobre la gravedad (MDSF, 2020). De acuerdo con la percepción sobre el riesgo de contagiarse por el virus, los porcentajes quedan de la siguiente manera: 


\section{Pregunta cuán de acuerdo estás con las siguientes afirmaciones:}

$\begin{array}{ccc}\text { Los jóvenes tienen alto } & \text { Los jóvenes tienen bajo } & \text { Los jóvenes normalmente } \\ \text { riesgo de contagiarse } & \text { riesgo de contagiarse } & \text { no se contagian }\end{array}$
$74 \%$ $34 \%$ $29 \%$

Fuente: Ministerio de Desarrollo Social y Familia, 2020, p. 6.

Para dar a conocer los resultados de esta encuesta, se presenta bajo el siguiente enunciado: «Encuesta del Ministerio de Desarrollo Social y Familia alerta que uno de cada tres jóvenes cree que no se contagiará de Covid-19»» (MDSF, 28 de abril, 2020). La prensa escrita también utilizó esta referencia como titular de la noticia (Lizana, 25 de abril, 2020), poniendo énfasis en el grupo cuya percepción frente al riesgo es menor y que, por ende, puede ser cuestionable con mayor facilidad. Dicho énfasis sostiene esta percepción juvenil de tener menor riesgo de contagiarse, pese a que la mayoría del grupo reconoce el riesgo del contagio, pareciendo entonces que el vínculo entre jóvenes y bajo percepción de riesgo es una condición innata a este grupo de la población.

Desde el ejercicio reflexivo, destacamos que la prensa escrita en este contexto de pandemia comprende lo juvenil como condición natural (Duarte, 2012), donde predominan tres ideas que se fundamentan desde una mirada adultocéntrica y que quisiéramos profundizar: i) la herencia biológica de la definición de la juventud; ii) la estigmatización de los grupos juveniles, y iii) la lectura al contexto de pandemia desde un conflicto generacional entre jóvenes y adultos. 


\subsection{LA HERENCIA BIOLÓGICA DE LA DEFINICIÓN DE LA JUVENTUD}

Es frecuente la alusión a la edad al momento de identificar a las personas jóvenes en el desarrollo de una noticia, utilizando el dato etario como referencia o marcador de lo juvenil (Krauskopf, 2015). Bajo esta perspectiva, un rango de edad delimita quiénes son y no son jóvenes en la población, levantando una frontera desde donde surgen algunos ritos sociales, como el paso de la minoría a la mayoría de edad, que en el caso de Chile ocurre cuando se cumplen los 18 años. El uso de la edad como marcador para definir a las y los jóvenes no es estático ni sostenido en el tiempo o espacio, pues, tal como señala Bourdieu (1990), «la edad es un dato biológico socialmente manipulado y manipulable» (pp. 164-165). Se habla del manejo de la edad como marcador de lo juvenil, ya que asumimos que esta categorización está influida por factores sociales, políticos y económicos, todos ellos vinculados a las representaciones e imaginarios que se construyen sobre las juventudes.

Al analizar algunos titulares y enunciados de la prensa escrita que aluden a la edad, podemos visualizar su manejo, según diferentes contextos, en la definición de la condición juvenil. Un artículo del diario La Cuarta lleva por titular «¿Por qué el bicho atacaría con menos fuerza a los más peques?», y define «Más de 200 niños (hasta los 19 años) contagiados por coronavirus hay en Chile» (Pacheco, 10 de abril, 2020). Por su parte, La Tercera, al informar sobre los resultados de la encuesta que realizó el Ministerio de Desarrollo Social y Familia, pareciera definir la condición juvenil entre los 14 y 24 años de edad. Mientras que, cuando se alude a figuras públicas que han cumplido importantes roles de autoridad en este contexto, también se manipula la edad al hacer referencia a la condición de joven, por ejemplo, de Arturo Zúñiga, subsecretario de Redes Asistenciales del Ministerio de Salud, que tiene 36 años. La prensa lo define como «El joven subsecretario al que se le vino encima el coronavirus» (Minay, 13 de marzo, 2020), o el caso de Izkia Siches, quien, con 
34 años, La Tercera realiza un artículo con el titular «La joven presidenta del Colmed y contraparte de La Moneda» (Muñoz, 16 de marzo, 2020).

Por tanto, la condición juvenil está representada según el contexto de manera relacional con otros, dotado de ciertos sentidos, y la edad como un dato utilizado y manejado para dar un sustento biológico a dichos sentidos. En dicho manejo se puede develar una forma de mirar a la población juvenil desde una perspectiva de la transición, arraigada a una condición natural de carácter explicativo de ciertas conductas o formas de ser, donde la juventud como una etapa de tránsito de la vida para ser adulto y/o adulta se ha caracterizado por un «estado de sufrimiento, suspendida entre dos mundos [la niñez y la adultez], en una búsqueda del sentido y del valor de su existencia» (Breton, 2012: 17). Así, se define a la y/o el joven como inexperto en relación con el adulto, ya que al valorarse la experiencia sobre la base de la cantidad de años vinculados a una cierta vivencia - sea, por ejemplo, en lo laboral o en los estudios-, la experiencia del o la joven es subvalorada.

En este escenario de pandemia, los discursos desde lo biológico han adquirido mayor connotación de lo verdadero, presentándose como argumentos irrefutables desde la lógica del experto/a. El filósofo Alain Badiou (2020), al finalizar su escrito en el controversial libro elaborado en periodo de pandemia La sopa de Wuhan, señala:

Demos crédito, incluso y sobre todo confinados, únicamente a las verdades verificables de la ciencia y a las perspectivas fundadas sobre una nueva política, de sus experiencias localizadas y de su objetivo estratégico. (p. 78)

Sin embargo, aquello catalogado como científico, basado en lo biológico, también está amalgamado de imaginarios y representaciones socialmente construidos. De este modo, la herencia biológica de la definición 
de la juventud sustentada en el uso de la edad cronológica como dato explicativo y compresivo (Filardo, 2018), también puede adquirir esta connotación de verdad difícilmente cuestionable, siendo que su manejo está cargado de representaciones y modos de comprender, en este caso, a los grupos juveniles.

\subsection{ESTIGMATIZACIÓN DE LOS GRUPOS JUVENILES}

Los estigmas sociales sobre la población juvenil también dan cuenta de dicha herencia biológica que conlleva la definición de juventud. Entendemos como estigmas aquellas imágenes elaboradas desde apariencias y miradas preconcebidas por otras y otros, que se fundan en prejuicios (Duarte, 2012). Si consideramos determinados estigmas sobre las personas jóvenes, se corre el riesgo de desarrollar investigaciones y/o difusión de noticias que permiten la confirmación «científica» y naturalización de dichas concepciones.

La prensa escrita, por ejemplo, en ningún momento problematiza los resultados de la encuesta realizada por el Ministerio de Desarrollo Social y Familia respecto a la percepción de jóvenes frente al riesgo de contagio, considerando a la población juvenil bajo el estigma de «irresponsables». Dicho estigma se fundamenta bajo el concepto de moratoria psicosocial (Erikson, 1977), que explica que las y los jóvenes poseen una cierta permisividad entre la madurez social y la madurez biológica, y a partir de este enunciado, proveniente de la psicología, se justifica como condición natural esperable la irresponsabilidad como parte del actuar juvenil.

Algunos diarios nacionales dieron a conocer las masivas fiestas que se realizaron en Estados Unidos durante los días que se registraron las más altas tasas de contagio dentro del país. A modo de titular, se anuncia: «Para ser 
inmunes: Así son las fiestas de los jóvenes de Estados Unidos para contagiarse el COVID-19» y, parafraseando a alguna de sus autoridades locales:

(...) los asistentes a las fiestas COVID-19 son jóvenes, una población que está en riesgo, porque se muestra más reacia a practicar el distanciamiento social, que es una de las principales medidas de prevención ante la pandemia. (Ibuitrarcia, 8 de mayo, 2020)

En este contexto, podemos ver que se caracteriza a las y los jóvenes como un grupo social con mayores posibilidades de contagiar a otros, debido a que son más «sociables». En una entrevista realizada el 19 de marzo al infectólogo de la Universidad de Harvard Eric Feigl-Ding, este afirma:

(...) el problema es que los jóvenes son probablemente 10 veces más activos y sociales que los ancianos, y pueden infectar a 10 veces más personas, especialmente si el COVID-19 es leve y los adultos jóvenes no lo notan. (En Parra, 19 de marzo, 2020)

Estos estigmas -incluso referenciados por personas ligadas al mundo de la ciencia - se articulan como una imagen que predomina al momento de definir lo juvenil en contexto de pandemia, promoviendo una mirada que atribuye características transversales a este grupo social. De esta manera, se deshumaniza a las personas jóvenes, negando la diversidad de expresiones y significaciones del entramado complejo que surge a raíz de este grupo social (Duarte, 2012). Esta mirada se plantea desde matices opuestos, tal y como lo proyectan en su investigación Muñoz, Durán y Thayer (2014), donde las «singularidades coexisten con totalizaciones relativas a los jóvenes chilenos, y en donde la descripción y tratamiento de las noticias se vincula a valorizaciones y rechazos; presencias y ausencias; ruidos y silencios que visibilizan e invisibilizan, destacan o etiquetan juventud» (p. 108). 
Durante el periodo de pandemia, vemos cómo se continúa visibilizando la juventud empobrecida de nuestro país bajo el estigma del «joven delincuente». Un ejemplo de ello es el titular del diario The Clinic (9 de abril, 2020), que señala «Detienen por cuarta vez a joven infringiendo cuarentena en Chillán», aclarando que «el joven saldría a la calle para delinquir, ya que cuenta con antecedentes por delitos contra la propiedad» (Ibíd.). Se podría decir, entonces, que hay una reducción en la mirada hacia lo delictual, naturalizando el delito a la figura del joven-pobre-delincuente (Muñoz, Durán y Thayer, 2014), que ahora además se construye como una figura mediática (Gentile, 2011).

Tanto antes como durante la pandemia, la estigmatización ha adquirido un carácter de clase, al ser un foco de atención la juventud que comete actos delictivos, relacionándola con los sectores más empobrecidos del país. De esta manera, se identifican las situaciones de violencia, delincuencia o vandalismo como representativos de las juventudes de sectores más vulnerados, potenciándose la figura del «joven delincuente», «el joven excluido», que vive en territorios empobrecidos, en condiciones de vulnerabilidad social o marginado del sistema (Dupret, 2010), aquel sujeto desviado o anómico (Durkheim, 1897). Para el contexto argentino, por ejemplo, Gentile (2011) señala que la construcción mediática de la figura del joven pobre y delincuente ha conllevado a definir un carácter juvenil de un hecho delictivo independiente de la edad, que se condensa en imágenes como el pibe chorro. 


\subsection{LA PANDEMIA DESDE UN CONFLICTO}

GENERACIONAL

La estigmatización de los grupos juveniles incide en sus formas de visibilización y, promoviendo una lectura relacional con otras generaciones, se destaca un carácter conflictivo que es significado como un problema social. Esta lectura ha estado presente en el discurso de la prensa escrita en contexto de pandemia, visibilizando las prácticas de los grupos juveniles como un potencial peligro social para la crisis que estamos habitando.

Esta situación de crisis agudiza la lectura desde la conflictividad generacional, posicionando a las y los jóvenes en una permanente tensión para el orden en el contexto de pandemia. De este modo, la prensa escrita, al referirse a las y los jóvenes, enfatiza en el llamado a la «responsabilidad» y al respeto por las normas de confinamiento:

(...) la falsa creencia de la inmunidad en jóvenes, está haciendo que la cifra siga aumentando diariamente, ya que las personas menores de 40 años siguen saliendo a la calle y se han transformado en un vehículo de distribución del virus. (Jaime Mañalich, ministro de Salud, en 24 Horas, 28 de mayo, 2020).

(...) la población joven no está en primera línea, porque no es la de mayor riesgo (...) nos encontramos con que confunden el hecho de no enfermarse gravemente, con el hecho de no contagiarse. (Carol Brown, subsecretaria de la Niñez, en CNN, 26 de abril, 2020)

Al leer la pandemia desde el conflicto generacional, nos podemos dar cuenta de que, con el paso del tiempo, las representaciones construidas sobre la base de estigmas hacia los grupos considerados en condición de minoría, como las y los jóvenes, irán cobrando cierta independencia de la edad de los sujetos involucrados en el conflicto (Gentile, 2011). Por lo tanto, la edad pierde rigidez al definir la juventud, transformándose en un dato numérico representativo de 
ciertas características que tensionan el entramado social y profundizan las condiciones de dominación. De esa manera, en los enunciados citados, la utilización del concepto de joven/jóvenes se vincula con la acción riesgosa por sobre la definición etaria.

La presentación de dicha conflictividad puede incluso quedar graficada desde la culpabilización, tal como se puede ver en la noticia de El Mostrador que informa sobre el caso en Argentina, cuyo titular anuncia: «COVID-19 en Argentina: joven contagió y causó la muerte de su abuelo tras haber asistido a una fiesta vulnerando la cuarentena» (en El Mostrador, 4 de mayo, 2020), donde se describe la situación de la siguiente manera:

Un joven de 24 años, identificado como Eric Luciano Torales, arriesga una pena de hasta 5 años de prisión por haber infringido la cuarentena obligatoria participando de una fiesta de cumpleaños de su prima tras haber llegado a Argentina desde Estados Unidos, instancia en la que contagió de COVID-19 a su abuelo, quien posteriormente falleció. (En El Mostrador, 4 de mayo, 2020).

A esto podemos sumar algunos reportes que anunció la prensa sobre fiestas y eventos realizados en Chile en período de cuarentena, considerando las palabras del subsecretario Arturo Zúñiga, quien sostiene:

Es muy difícil enfrentar una pandemia como la que estamos viviendo. Pero se hace aún más cuesta arriba sin responsabilidad ciudadana (...) De esos 400 jóvenes muy pocos serán hospitalizados, pero pueden provocar que sus padres o abuelos sean conectados a ventilación y un 10\% fallecerá. (En Latorre, 3 de mayo, 2020)

El conflicto se expresa como un choque entre aquello que socialmente se espera como expectativa social sobre las y los jóvenes en contexto de pandemia, fundado desde estigmatizaciones que llegan a un punto donde es 
difícil escapar de las etiquetas (Dupret, 2010). Bajo esta lógica, se invisibiliza a las juventudes desde una perspectiva multifactorial y de manera relacional con otras generaciones (Gentile, 2011), incluso se presenta como un sector social peligroso para los demás, sobre todo para las y los adultos mayores. Así, la prensa fomenta una mirada de enfrentamiento entre generaciones en contexto de pandemia, en lugar de promover lógicas cooperativas entre generaciones.

Lejos de pensar en puntos de encuentro y nuevas posibilidades de comprender lo intergeneracional como un entramado de vínculos donde pudiese primar el cuidado mutuo, las formas que se presentan como solución a este conflicto tienen que ver con el castigo social e incluso la represión, tal como refiere una autoridad local en la prensa: «(...) Si ellos [los jóvenes] no quieren entender, habrá que agarrarlos a peñascazos» (La Cuarta, 12 de mayo, 2020).

Esta lectura de prensa como conflicto generacional visibiliza la idea de lo juvenil como aquello que pone en peligro el bien común, profundizando la condición de dominio del mundo adulto.

\section{REFLEXIONES FINALES}

El ejercicio reflexivo respecto a lo que dice la prensa escrita-digital en el contexto de pandemia sobre las y los jóvenes, nos permite identificar algunas ideas que dan luces sobre los modos de visibilizar a las juventudes, donde predomina una mirada de lo juvenil como condición natural producto de una herencia biológica. Esta forma de comprender lo juvenil promueve estigmas sociales y nos presenta el contexto desde la conflictividad generacional.

A modo de finalizar el escrito, se presentan algunos ejes de análisis para abrir las reflexiones desarrolladas. 
En primer lugar, es importante reconocer que las formas de visibilización de las y los jóvenes, por parte de los medios de comunicación masiva, dan cuenta de una idea de lo juvenil en un contexto adultocéntrico, donde se fortalecen ciertos imaginarios enraizados en la sociedad. De esta manera, no cuestionan ni profundizan en la forma hegemónica que se concibe la juventud, predominando así una mirada estigmatizante, asentada en un sistema de dominio social intersectado por otros sistemas, tales como el género, la raza $^{8}$ y la clase.

En segundo lugar, y en línea con el argumento anterior, se considera que la utilización de la palabra juventud en pandemia ha sido definida por la prensa escrita digital desde lo disruptivo, lo riesgoso (o arriesgado) y lo peligroso, comprendiendo que se trata de un grupo social que puede incluso atentar contra la salud y el bienestar de otras personas.

Por último, consideramos que las políticas públicas de juventud en la pandemia han estado inclinadas hacia la responsabilización y la sanción individual, en un contexto económico y político fuertemente cuestionado, donde el debate por lo colectivo requiere cada vez mayor atención.

Si proyectamos como desafío un análisis más complejo e integral, podríamos ver que esta perspectiva de la política pública - y la falta de medidas del gobierno - invisibiliza las condiciones desiguales que las personas viven en el escenario social de pandemia y la consecuente necesidad de confinamiento, siendo principalmente afectadas aquellas que se encuentran, desde los diferentes sistemas de dominio, en una condición desvalorizada, como por ejemplo: i) género: las mujeres y el aumento de la carga laboral en el ámbito doméstico y de crianza durante el aislamiento social, junto con el aumento de situaciones de violencia y maltrato por parte de sus parejas; ii) clase: el incumplimiento del confinamiento se ha dado mayormente en los

\footnotetext{
${ }^{8}$ Los cuales no fueron abordados en esta oportunidad.
} 
sectores más empobrecidos, ya que muchos no cuentan con un trabajo regular y deben salir a trabajar para poder mantener condiciones mínimas vinculadas a la alimentación o supervivencia, lo que vuelve aún más crudo el escenario; iii) raza: los sectores migrantes racializados se han marginado en la posibilidad de legalizar sus documentos y estadía en el país, privándose del acceso a una vivienda y encontrándose muchas y muchos en situación de hacinamiento $\mathrm{y}$ nula seguridad laboral; iv) territorio: existe una diferenciación de los territorios a lo largo del país, y el foco de la política pública tiende a priorizar a la Región Metropolitana — donde se ubica la capital del país - con respecto a las otras regiones, invisibilizando la realidad de los sectores rurales; v) generación: ya hemos visualizado desde un ámbito cómo esta crisis afecta a los sectores juveniles, pero también habría que considerar a la niñez y la vejez ${ }^{9}$.

Por último, y a modo de ampliar la discusión, creemos que la mirada reduccionista desde la cual se han construido políticas públicas o iniciativas estatales para enfrentar el contexto de pandemia genera un alto porcentaje de incumplimiento de las normativas, ya que no se logra abordar las problemáticas reales de las personas, permitiendo trasladar la responsabilidad desde un Estado garante de condiciones mínimas de una vida digna - tanto en salud, trabajo, alimentación, educación- hacia el actuar individual de las personas, categorizándolas bajo una mirada sancionadora y negativa, sobre todo a los grupos juveniles.

RECIBIDO: 29 DE MAYO DE 2020

ACEPTADO: 22 DE JULIO DE 2020

\footnotetext{
${ }^{9}$ Queda claro que este último punto describe a los sistemas de dominio en contexto de pandemia, y que este artículo solo abordó el elemento generacional, quedando como desafío el profundizar — en futuros ejercicios - sobre el género, la clase, la raza y el territorio en este mismo contexto.
} 


\section{BIBLIOGRAFÍA}

AguilerA, O. (2009). Los estudios sobre juventud en Chile: coordenadas para un estado del arte. Última Década, 17(31), 109-127. http://dx.doi.org/10.4067/S0718-22362009000200007

AguilerA, Ó. (2014). La idea de juventud en Chile en el siglo XX. Aproximación genealógica al discurso de las revistas de juventud. Anagramas, 12(24), 141-160.

Alvear, F. y Mirando, C. (2006). Movilización de estudiantes secundarios: síntomas de una crisis neoliberal en Chile. Pluma y Pincel, 191. http://www.opech.cl/bibliografico/Participacion_Cultura_Escolar/movili zacion_secundarios_crisis_neoliberal_chile.pdf

Badiou, A. (2020). Sobre la situación epidémica. En G. AgAmben, S. ZizeK, J.-L. Nancy, F. Berardi, S. López Petit, J. Butler, . . . P. B. Preciado, La sopa de Wuhan (pp. 67-78). ASPO.

BAezA, J. y SANDOval, M. (2009). Nuevas prácticas políticas en jóvenes de Chile: conocimientos acumulados 2000-2008. Revista Latinoamericana de Ciencias Sociales, 2(2), 1379-1403.

Bourdieu, P. (1990). La juventud no es más que una palabra. En P. BourdiEU, Sociología y Cultura. México, D. F.: Grijalbo.

Breton, D. L. (2012). La edad solitaria. Adolescencia y sufrimiento. Santiago Chile: LOM Ediciones.

Bustos, P. (1997). Jóvenes: reflexiones en torno al tema de la participación y la política. Última Década, 7, 97-122.

CANDiA, E. (2004). El movimiento político sin voto de los jóvenes en Chile. Observatorio de la Juventud, 4, INJUV.

CRiado, M. (1998). Producir la juventud. Crítica de la sociología de la juventud. Madrid: Istmo.

DuARTE, C. (2012). Sociedades adultocéntriscas: sobre sus orígenes y reproducción. Última Década, 20(36), 99-125.

- (2016). Genealogía del adultocentrismo. La constitución de un patriarcado adultocéntrico. En K. DUARTE y C. ÁlvareZ, Juventudes en Chile. Mirada de Jóvenes que investigan (pp. 17-47). Social-Ediciones.

DuPRET, M.-A. (2010). Criminalización de la juventud marginal. Universitas. Revista de Ciencias Sociales y Humanas, 13, 69-94.

DurkheIM, É. (1897). El suicidio. Estudio de sociología. México, D. F. (2004): Ediciones Coyoacán.

ERIKSON, E. (1977). Identidad, juventud y crisis. Buenos Aires: Paidós. 
FILARDO, V. (2018). Juventud, juventudes, jóvenes: esas palabras. Última Década, 26(50), 109-123. Recuperado de https://dx.doi.org/10.4067/S0718-22362018000300109

FUENTES, C. (2006). Juventud y participación política en el Chile actual. Observatorio de Juventud, 3, INJUV.

GENTILE, M. (2011). Los procedimientos discursivos para la construcción mediática de la figura del joven pobre y delincuente. El «caso Jonathan». Última Década, 19(34), 93-119.

GHIARDO, F. (2004). Generaciones y juventud: una relectura desde Manheim y Ortega y Gasset. Última Década (20), 11-46.

IGARZA, R. (2010). Nuevas formas de consumo cultural: por qué las redes sociales están ganando la batalla de las audiencias. Comunicação, Mídia e Consumo, 7(20), 59-90.

KRAUSKOPF, D. (Junio de 2015). Los marcadores de juventud: la complejidad de las edades. Última Década, (42), 115-128.

Ministerio de Desarrollo Social y FAmilia. (2020). Radiografia nacional de jóvenes frente a la crisis sanitaria COVID-19. Gobierno de Chile.

MuÑOz, G. (2010). La comunicación en los mundos de vida juveniles. Revista Latinoamericana de Ciencias Sociales, Niñez y Juventud, 5(1).

MuÑoz, V., DurÁn C. y THAYER, E. (2014). Los jóvenes populares urbanos frente a la prensa escrita y digital: Distorsiones, identificaciones, distancias y silencios. Última Década, 22(41), 89-123.

TORRES, R. (2010). Juventud, resistencia y cambio social: el movimiento de estudiantes secundarios como un «actor político» en la sociedad chilena post-Pinochet (1986-2006). Presentado en el VI Congreso CEISAL, Tolouse, Francia. Recuperado de https://halshs.archivesouvertes.fr/file/index/docid/498869/filename/Rod rigoTorres.pdf

Urbano F., Rosas, P. y MundacA, R. (2006). Los jóvenes, la política y el espacio público. La transición y la emergencia del sujeto periférico. Concepción: Escaparate/ILAES. 


\section{Prensa Utilizada}

24 Horas. (28 de mayo, 2020). Mañalich por cuarentena en RM: «Si no logramos este convencimiento, se puede alargar y alargar». 24 Hrs. TVN. Recuperado de https://www.24horas.cl/coronavirus/manalich-porcuarentena-en-rm-si-no-logramos-este-convencimiento-se-puedealargar-y-alargar-4209735

Bío-Bío. (27 de mayo, 2020). «Gobierno endurece mensaje a jóvenes: Se enferman, demandan hospitalización y quitan cupo a mayores». Recuperado

de https://www.biobiochile.cl/noticias/nacional/chile/2020/05/27/gobiernoendurece-mensaje-jovenes-se-enferman-demandan-hospitalizacion-lequitan-cupo-mayores.shtml

Ceballos, C. (23 de abril, 2020). Ministro de Educación y retorno a clases en medio de la pandemia: «Los niños que se contagian no corren mayor riesgo». $E l \quad$ Desconcierto. Recuperado de https://www.eldesconcierto.cl/2020/04/23/ministro-de-educacion-yretorno-a-clases-en-medio-de-la-pandemia-los-ninos-que-se-contagianno-corren-mayor-riesgo/

CNN. (26 de abril, 2020). «Subsecretaria de la Niñez analiza encuesta a jóvenes sobre el coronavirus: "No le temen a perder el año escolar"». CNN Chile. Recuperado de https://www.cnnchile.com/lodijeronencnn/subsecretaria-de-la-ninezencuesta-jovenes-coronavirus-perder-ano-escolar_20200426/

Delgado, F. (15 de marzo, 2020). Gobierno cede a la presión y anuncia suspensión de clases por dos semanas ante Coronavirus. Bío-Bío. Recuperado https://www.biobiochile.cl/noticias/nacional/chile/2020/03/15/president e-sebastian-pinera-anuncia-suspension-de-clases-por-dos-semanas-antecoronavirus.shtml

EFE. (18 de marzo, 2020). OMS advierte que hay más de 200 mil contagiados en el mundo: "Este coronavirus no solo mata gente mayor, un número significativo de jóvenes ha muerto». El Mostrador. Recuperado de https://www.elmostrador.cl/dia/2020/03/18/oms-advierte-que-hay-masde-200-mil-contagiados-en-el-mundo-este-coronavirus-no-solo-matagente-mayor-un-numero-significativo-de-jovenes-ha-muerto/

EFE/The Clinic. (20 de marzo, 2020). OMS cifra en más de 210.000 los casos de Coronavirus en el planeta y pide a los jóvenes que no se confíen. The Clinic. Recuperado de https://www.theclinic.cl/2020/03/20/oms-cifraen-mas-de-210-000-los-casos-de-coronavirus-y-pide-a-los-jovenes-queno-se-confien/ 
El Desconcierto. (28 de marzo, 2020). Estudiantes de la Universidad de Chile aprueban "paro online" por problemas de clases remotas. El Desconcierto. Recuperado de https://www.eldesconcierto.cl/2020/03/28/estudiantes-de-launiversidad-de-chile-aprueban-paro-online-por-problemas-de-clasesremotas/

El Mostrador. (4 de mayo, 2020). COVID-19 en Argentina: joven contagió y causó la muerte de su abuelo tras haber asistido a una fiesta vulnerando la cuarentena. El Mostrador. Recuperado de https://www.elmostrador.cl/noticias/2020/05/04/covid-19-en-argentinajoven-contagio-y-causo-la-muerte-de-su-abuelo-tras-haber-asistido-auna-fiesta-vulnerando-la-cuarentena/

. (18 de enero, 2020). A tres meses del estallido: realizan marcha «en silencio contra la represión» en Plaza de la Dignidad. El Mostrador. Recuperado de https://www.elmostrador.cl/noticias/multimedia/2020/01/18/a-tresmeses-del-estallido-realizan-marcha-en-silencio-contra-la-represion-enplaza-de-la-dignidad/

Europa Press. (20 de marzo, 2020). OMS apunta a los jóvenes: «No son invencibles». La Tercera. Recuperado de https://www.latercera.com/que-pasa/noticia/oms-apunta-a-los-jovenesno-son-invencibles/55ZZGZX3XNC4DIH2Y5ATTFUZAE/

KOKALY, I. (21 de enero, 2020). ¡Gracias, Valiente Juventud!: La historia detrás de la persona con el cartel. Recuperado de https://www.primeralineaprensa.cl/?p=4755

LA CUARTA. (12 de mayo, 2020). «Habrá que agarrarlos a peñascazos»: la dura amenaza de alcaldesa a jóvenes que hacen fiestas. La Cuarta. Recuperado de https://www.lacuarta.com/cronica/noticia/alcaldesacontagios-fiestas/495261/

LATORRE, C. (3 de mayo, 2020). «Se creen invencibles»: gobierno condena multitudinaria fiesta clandestina en Maipú. La Cuarta. Recuperado de https://www.lacuarta.com/cronica/noticia/gobierno-condena-fiestaclandestina/490912/

IBUitrarcia. (8 de mayo, 2020). Para ser inmunes: Así son las fiestas de los jóvenes de Estados Unidos para contagiarse el Covid-19. El Ciudadano. Recuperado de https://www.elciudadano.com/reportaje-destacadomejor-periodismo/para-ser-inmunes-asi-son-las-fiestas-de-los-jovenesde-estados-unidos-para-contagiarse-el-covid-19/05/08/

LEPPE, N. (16 de abril, 2020). Iban a una fiesta y se les pasó la hora: jóvenes fueron sorprendidos violando toque de queda en Las Condes. Publimetro.

Recuperado

de 
https://www.publimetro.cl/cl/social/2020/04/16/las-condes-cuarentenacoronavirus-jovenes-sorprendidos-autos-rompiendo-toque-queda.html

LizANA, A. M. (25 de abril, 2020). Encuesta revela que 1 de cada 3 jóvenes cree que no se contagiará de Covid-19. El Dínamo. Recuperado de https://www.eldinamo.cl/nacional/2020/04/25/encuesta-revela-que-1de-cada-3-jovenes-cree-que-no-se-contagiara-de-covid-19/

LVDM. (3 de mayo, 2020). [VIDEO] Jóvenes maipucinos realizaron masiva fiesta electrónica en el día con más contagios por COVID-19 en Chile. La voz de Maipú. Recuperado de https://avozdemaipu.cl/video-jovenesmaipucinos-realizaron-masiva-fiesta-electronica-en-el-dia-con-mascontagios-por-covid-19-en-chile/

MDSF. (28 de abril, 2020). Encuesta del Ministerio de Desarrollo Social y Familia alerta que uno de cada tres jóvenes cree que no se contagiará de Covid-19. Ministerio de Desarrollo Social y Familia. Recuperado de http://www.desarrollosocialyfamilia.gob.cl/noticias/encuesta-delministerio-de-desarrollo-social-y-familia-alerta-que-uno-de-cada-tresjovenes-cree-que-

Meganoticias. (26 de marzo, 2020). Ministro de Educación y posible «paro online»: «Lo que corresponde es buscar mecanismos de colaboración». Recuperado de https:/www.meganoticias.cl/nacional/296282-ministroeducacion-raul-figueroa-paro-online-coronavirus.html

MinAY, S. (13 de marzo, 2020). Arturo Zúñiga, el joven subsecretario al que se le vino encima el coronavirus. La Tercera. Recuperado de https://www.latercera.com/la-tercera-pm/noticia/arturo-zuniga-el-jovensubsecretario-al-que-se-le-vino-encima-elcoronavirus/N4RA7YOX65G67BDKDCNG2MNAOY/

MuÑoz, A. (16 de marzo, 2020). Izkia Siches, la joven presidenta del Colmed y contraparte de La Moneda. La Tercera. Recuperado de https://www.latercera.com/la-tercera-pm/noticia/reuniones-porreferendum-y-contraparte-de-la-moneda-el-activo-rol-de-izkia-sichesen-la-emergencia/TS2GU27YWJBLBBVUZVY2USFLYM/

PACHECO, C. (10 de abril, 2020). ¿Por qué el bicho atacaría con menos fuerza a los más peques? La Cuarta. Recuperado de https://www.lacuarta.com/cronica/noticia/bicho-menos-fuerza-maspeques/482508/

PARRA, F. (19 de marzo, 2020). Jóvenes serían el principal foco de infección del coronavirus en Chile y el mundo. La Tercera. Recuperado de https://www.latercera.com/que-pasa/noticia/jovenes-serian-el-principalfoco-de-infeccion-del-coronavirus-en-chile-y-elmundo/5GIF5RA6DVCALA7I3LL3X4E6XY/ 
SAID, C. (17 de marzo, 2020). Escolares anuncian suspensión de protestas tras restricciones a la circulación producto del Covid-19. La Tercera. Recuperado de https:/www.latercera.com/nacional/noticia/escolaresanuncian-suspension-de-protestas-tras-restricciones-a-la-circulacionproducto-del-covid-19/KMBKCBGH65GMPILQZQME4C6TXA/

Scherman, A., Correa, T. y Peña y Lillo, M. (10 de enero, 2020). 2019: el año en que los jóvenes se volvieron a movilizar. La Tercera. Recuperado de https://www.latercera.com/tendencias/noticia/2019-elano-en-que-los-jovenes-se-volvieron-a-movilizar/969461/

SEPÚlvEDA, P. (12 de marzo, 2020). Sin miedo al riesgo: jóvenes aprovechan ofertas de vuelos en medio de pandemia por coronavirus. La Tercera. Recuperado de https://www.latercera.com/que-pasa/noticia/sin-miedoal-riesgo-jovenes-aprovechan-ofertas-de-vuelos-en-medio-de-pandemiapor-coronavirus/QUJIDNWY2VGJ7EGVDF52G63XIY/

THE ClinIC. (09 de abril, 2020). Detienen por cuarta vez a joven infringiendo cuarentena en Chillán. The Clinic. Recuperado de https://www.theclinic.cl/2020/04/09/detienen-por-cuarta-vez-a-joveninfringiendo-cuarentena-en-chillan/ 


\section{Anexos}

\section{ANEXO 1: RESUMEN DE SISTEMATIZACIÓN}

\begin{tabular}{|c|c|c|c|c|}
\hline & Fecha & Medio & Título & Link \\
\hline 1 & $05-03-2020$ & Interferencia & $\begin{array}{l}\text { Entendiendo a Piñera: los } \\
\text { episodios clave de su infancia } \\
\text { y juventud que marcaron su } \\
\text { personalidad }\end{array}$ & $\begin{array}{l}\text { https://interferencia.cl/articulos } \\
\text { /entendiendo-pinera-los- } \\
\text { episodios-clave-de-su-infancia- } \\
\text { y-juventud-que-marcaron-su }\end{array}$ \\
\hline 2 & 08-03-2020 & La Tercera & $\begin{array}{l}\text { Un tercio de las mujeres } \\
\text { jóvenes que no estudia ni } \\
\text { trabaja fuera de casa lo hace } \\
\text { para cuidar a sus hijos }\end{array}$ & $\begin{array}{l}\text { https://www.latercera.com/puls } \\
\text { o/noticia/un-tercio-de-las- } \\
\text { mujeres-jovenes-que-no- } \\
\text { estudia-ni-trabaja-fuera-de- } \\
\text { casa-lo-hace-para-cuidar-a-sus- } \\
\text { hijos/3BUSRMJKDRFWLDE } \\
\text { RKTYEL24W6Q/ }\end{array}$ \\
\hline 3 & 08-03-2020 & La Tercera & $\begin{array}{l}\text { ¿Qué opinan las jóvenes } \\
\text { nórdicas? }\end{array}$ & $\begin{array}{l}\text { https://www.latercera.com/opi } \\
\text { nion/noticia/que-opinan-las- } \\
\text { jovenes- } \\
\text { nordicas/RMZ2OZG525CTXJ } \\
\text { EDJRUHFB65BU/ }\end{array}$ \\
\hline 4 & $12-03-2020$ & La Tercera & $\begin{array}{l}\text { Sin miedo al riesgo: jóvenes } \\
\text { aprovechan ofertas de vuelos } \\
\text { en medio de pandemia por } \\
\text { coronavirus }\end{array}$ & $\begin{array}{l}\text { https://www.latercera.com/que } \\
\text {-pasa/noticia/sin-miedo-al- } \\
\text { riesgo-jovenes-aprovechan- } \\
\text { ofertas-de-vuelos-en-medio- } \\
\text { de-pandemia-por- } \\
\text { coronavirus/QUJIDNWY2VGJ } \\
\text { 7EGVDF52G63XIY/ }\end{array}$ \\
\hline 5 & $15-03-2020$ & $\begin{array}{l}\text { Bío-Bío } \\
\text { Chile }\end{array}$ & $\begin{array}{l}\text { Gobierno cede a la presión y } \\
\text { anuncia suspensión de clases } \\
\text { por dos semanas ante } \\
\text { Coronavirus }\end{array}$ & $\begin{array}{l}\text { https://www.biobiochile.cl/noti } \\
\text { cias/nacional/chile/2020/03/15/ } \\
\text { presidente-sebastian-pinera- } \\
\text { anuncia-suspension-de-clases- } \\
\text { por-dos-semanas-ante- } \\
\text { coronavirus.shtml }\end{array}$ \\
\hline 6 & $13-03-2020$ & La Tercera & $\begin{array}{l}\text { Arturo Zúñiga, el joven } \\
\text { subsecretario al que se le vino } \\
\text { encima el coronavirus }\end{array}$ & $\begin{array}{l}\text { https://www.latercera.com/la- } \\
\text { tercera-pm/noticia/arturo- } \\
\text { zuniga-el-joven-subsecretario- } \\
\text { al-que-se-le-vino-encima-el- } \\
\text { coronavirus/N4RA7YOX65G6 } \\
\text { 7BDKDCNG2MNAOY/ }\end{array}$ \\
\hline 7 & $16-03-2020$ & The Clinic & $\begin{array}{l}\text { Gobierno denuncia a joven que } \\
\text { viajó en avión a Temuco a } \\
\text { pesar de presentar síntomas de } \\
\text { coronavirus }\end{array}$ & $\begin{array}{l}\text { https://www.theclinic.cl/2020/ } \\
\text { 03/16/gobierno-denuncia-a- } \\
\text { joven-que-viajo-en-avion-a- } \\
\text { temuco-a-pesar-de-presentar- } \\
\text { sintomas-de-coronavirus/ }\end{array}$ \\
\hline 8 & $16-03-2020$ & La Tercera & $\begin{array}{l}\text { Izkia Siches, la joven } \\
\text { presidenta del Colmed y } \\
\text { contraparte de La Moneda }\end{array}$ & $\begin{array}{l}\text { https://www.latercera.com/la- } \\
\text { tercera-pm/noticia/reuniones- } \\
\text { por-referendum-y-contraparte- }\end{array}$ \\
\hline
\end{tabular}




\begin{tabular}{|c|c|c|c|c|}
\hline & & & & $\begin{array}{l}\text { de-la-moneda-el-activo-rol-de- } \\
\text { izkia-siches-en-la- } \\
\text { emergencia/TS2GU27YWJBL } \\
\text { BBVUZVY2USFLYM/ }\end{array}$ \\
\hline 9 & $18-03-2020$ & El Mostrador & $\begin{array}{l}\text { OMS advierte que hay más de } \\
200 \text { mil contagiados en el } \\
\text { mundo: «Este coronavirus no } \\
\text { solo mata gente mayor, un } \\
\text { número significativo de } \\
\text { jóvenes ha muerto» }\end{array}$ & $\begin{array}{l}\text { https://www.elmostrador.cl/dia } \\
/ 2020 / 03 / 18 / \text { oms-advierte-que- } \\
\text { hay-mas-de-200-mil- } \\
\text { contagiados-en-el-mundo-este- } \\
\text { coronavirus-no-solo-mata- } \\
\text { gente-mayor-un-numero- } \\
\text { significativo-de-jovenes-ha- }\end{array}$ \\
\hline 10 & $18-03-2020$ & The Clinic & $\begin{array}{l}\text { Mayor riesgo incluye a } \\
\text { fumadores y obesos: La } \\
\text { realidad de los pacientes } \\
\text { jóvenes infectados de } \\
\text { Coronavirus }\end{array}$ & $\begin{array}{l}\text { https://www.theclinic.cl/2020/ } \\
\text { 03/18/mayor-riesgo-incluye-a- } \\
\text { fumadores-y-obesos-la- } \\
\text { realidad-de-los-pacientes- } \\
\text { jovenes-infectados-de- } \\
\text { coronavirus/ }\end{array}$ \\
\hline 11 & $19-03-2020$ & La Tercera & $\begin{array}{l}\text { Jóvenes serían el principal foco } \\
\text { de infección del coronavirus en } \\
\text { Chile y el mundo }\end{array}$ & $\begin{array}{l}\text { https://www.latercera.com/que } \\
\text {-pasa/noticia/jovenes-serian-el- } \\
\text { principal-foco-de-infeccion- } \\
\text { del-coronavirus-en-chile-y-el- } \\
\text { mundo/5GIF5RA6DVCALA7I } \\
\text { 3LL3X4E6XY/ }\end{array}$ \\
\hline 12 & $20-03-2020$ & The Clinic & $\begin{array}{l}\text { OMS cifra en más de } 210.000 \\
\text { los casos de Coronavirus en el } \\
\text { planeta y pide a los jóvenes } \\
\text { que no se confíen. }\end{array}$ & $\begin{array}{l}\text { https://www.theclinic.cl/2020/ } \\
\text { 03/20/oms-cifra-en-mas-de- } \\
\text { 210-000-los-casos-de- } \\
\text { coronavirus-y-pide-a-los- } \\
\text { jovenes-que-no-se-confien/ }\end{array}$ \\
\hline 13 & $20-03-2020$ & La Tercera & $\begin{array}{l}\text { OMS apunta a los jóvenes: } \\
\text { «No son invencibles» }\end{array}$ & $\begin{array}{l}\text { https://www.latercera.com/que } \\
\text {-pasa/noticia/oms-apunta-a- } \\
\text { los-jovenes-no-son- } \\
\text { invencibles/55ZZGZX3XNC4 } \\
\text { DIH2Y5ATTFUZAE/ }\end{array}$ \\
\hline 14 & 22-03-2020 & La Tercera & $\begin{array}{l}\text { Sin miedo al riesgo: jóvenes } \\
\text { aprovechan ofertas de vuelos } \\
\text { en medio de pandemia por } \\
\text { coronavirus }\end{array}$ & $\begin{array}{l}\text { https://www.latercera.com/que } \\
\text {-pasa/noticia/sin-miedo-al- } \\
\text { riesgo-jovenes-aprovechan- } \\
\text { ofertas-de-vuelos-en-medio- } \\
\text { de-pandemia-por- } \\
\text { coronavirus/QUJIDNWY2VGJ } \\
\text { 7EGVDF52G63XIY/ }\end{array}$ \\
\hline 15 & 24-03-2020 & La Cuarta & $\begin{array}{l}\text { Abuela es la segunda víctima } \\
\text { del covid-19 }\end{array}$ & $\begin{array}{l}\text { https://www.lacuarta.com/cron } \\
\text { ica/noticia/abuela-covid-19- } \\
\text { victima/474913/ }\end{array}$ \\
\hline 16 & $25-03-2020$ & La Tercera & $\begin{array}{l}\text { Covid-19 en jóvenes afebriles: } \\
\text { las interrogantes que abre el } \\
\text { primer informe epidemiológico } \\
\text { de los casos chilenos }\end{array}$ & $\begin{array}{l}\text { https://www.latercera.com/naci } \\
\text { onal/noticia/covid-19-en- } \\
\text { jovenes-afebriles-la- } \\
\text { interrogantes-que-abre-el- } \\
\text { primer-informe- } \\
\text { epidemiologico-de-los-casos- } \\
\text { chilenos/F7PPPZVG5FFCRK } \\
\text { DMUUBQCVNGEU/ }\end{array}$ \\
\hline
\end{tabular}




\begin{tabular}{|c|c|c|c|c|}
\hline 17 & 26-03-2020 & $\begin{array}{l}\text { Meganoticia } \\
\mathrm{S}\end{array}$ & $\begin{array}{l}\text { Ministro de Educación y } \\
\text { posible «paro online»: «Lo que } \\
\text { corresponde es buscar } \\
\text { mecanismos de colaboración» }\end{array}$ & $\begin{array}{l}\text { https://www.meganoticias.cl/n } \\
\text { acional/296282-ministro- } \\
\text { educacion-raul-figueroa-paro- } \\
\text { online-coronavirus.html }\end{array}$ \\
\hline 18 & $28-03-2020$ & \begin{tabular}{|l|} 
El \\
Desconcierto
\end{tabular} & $\begin{array}{l}\text { Estudiantes de la Universidad } \\
\text { de Chile aprueban «paro } \\
\text { online» por problemas de } \\
\text { clases remotas }\end{array}$ & $\begin{array}{l}\text { https://www.eldesconcierto.cl/ } \\
\text { 2020/03/28/estudiantes-de-la- } \\
\text { universidad-de-chile-aprueban- } \\
\text { paro-online-por-problemas-de- } \\
\text { clases-remotas/ }\end{array}$ \\
\hline 19 & $\begin{array}{l}19-03- \\
2020\end{array}$ & La Tercera & $\begin{array}{l}\text { Jóvenes serían el principal foco } \\
\text { de infección del coronavirus en } \\
\text { Chile y el mundo }\end{array}$ & $\begin{array}{l}\text { https://www.latercera.com/que } \\
\text {-pasa/noticia/jovenes-serian-el- } \\
\text { principal-foco-de-infeccion- } \\
\text { del-coronavirus-en-chile-y-el- } \\
\text { mundo/5GIF5RA6DVCALA7I } \\
\text { 3LL3X4E6XY/ }\end{array}$ \\
\hline 20 & $20-03-2020$ & La Tercera & $\begin{array}{l}\text { OMS apunta a los jóvenes: } \\
\text { «No son invencibles» }\end{array}$ & $\begin{array}{l}\text { https://www.latercera.com/que } \\
\text {-pasa/noticia/oms-apunta-a- } \\
\text { los-jovenes-no-son- } \\
\text { invencibles/55ZZGZX3XNC4 } \\
\text { DIH2Y5ATTFUZAE/ }\end{array}$ \\
\hline 21 & $25-03-2020$ & La Tercera & $\begin{array}{l}\text { Covid-19 en jóvenes afebriles: } \\
\text { las interrogantes que abre el } \\
\text { primer informe epidemiológico } \\
\text { de los casos chilenos }\end{array}$ & $\begin{array}{l}\text { https://www.latercera.com/naci } \\
\text { onal/noticia/covid-19-en- } \\
\text { jovenes-afebriles-la- } \\
\text { interrogantes-que-abre-el- } \\
\text { primer-informe- } \\
\text { epidemiologico-de-los-casos- } \\
\text { chilenos/F7PPPZVG5FFCRK } \\
\text { DMUUBQCVNGEU/ }\end{array}$ \\
\hline 22 & $03-04-2020$ & La Cuarta & $\begin{array}{l}\text { Protegerán a los tatitas con el } \\
\text { termómetro en mano }\end{array}$ & $\begin{array}{l}\text { https://www.lacuarta.com/cron } \\
\text { ica/noticia/protegeran-los- } \\
\text { tatitas-termometro- } \\
\text { mano/479616/ }\end{array}$ \\
\hline 23 & 03-04-2020 & La Cuarta & $\begin{array}{l}\text { «Diseñada para matar a los } \\
\text { viejos y pobres»: las } \\
\text { reflexiones de Jorge González } \\
\text { desde la cuarentena }\end{array}$ & $\begin{array}{l}\text { https://www.lacuarta.com/espe } \\
\text { ctaculos/noticia/viejos-jorge- } \\
\text { gonzalez-desde/480053/ }\end{array}$ \\
\hline 24 & 04-04-2020 & La Tercera & $\begin{array}{l}\text { Minsal reporta por primera vez } \\
\text { fallecidos con menos de } 40 \\
\text { años }\end{array}$ & $\begin{array}{l}\text { https://www.latercera.com/naci } \\
\text { onal/noticia/minsal-reporta- } \\
\text { por-primera-vez-fallecidos- } \\
\text { con-menos-de-40- } \\
\text { anos/EZCOHBTDNNHZXC2 } \\
\text { M2HBIEWSMKY/ }\end{array}$ \\
\hline 25 & 06-04-2020 & $\begin{array}{l}\text { El } \\
\text { Ciudadano }\end{array}$ & $\begin{array}{l}\text { «Si lo hubieran atendido, mi } \\
\text { hijo estaría vivo»: Familia de } \\
\text { joven fallecido por Covid-19 } \\
\text { acusa negligencias }\end{array}$ & $\begin{array}{l}\text { https://www.elciudadano.com/ } \\
\text { chile/si-lo-hubieran-atendido- } \\
\text { mi-hijo-estaria-vivo-familia- } \\
\text { de-joven-fallecido-por-covid- } \\
\text { 19-acusa-negligencias/04/06/ }\end{array}$ \\
\hline 26 & 07-04-2020 & $\begin{array}{l}\text { El } \\
\text { Ciudadano }\end{array}$ & $\begin{array}{l}\text { COVID-19, tercera edad y } \\
\text { demencias: } 200 \text { mil personas } \\
\text { enfrentan una de las caras más } \\
\text { duras de la pandemia }\end{array}$ & $\begin{array}{l}\text { https://www.elciudadano.com/ } \\
\text { chile/covid-19-tercera-edad-y- } \\
\text { demencias-200-mil-personas- } \\
\text { enfrentan-una-de-las-caras- }\end{array}$ \\
\hline
\end{tabular}




\begin{tabular}{|c|c|c|c|c|}
\hline & & & & $\begin{array}{l}\text { mas-duras-de-la- } \\
\text { pandemia/04/07/ }\end{array}$ \\
\hline 27 & 07-04-2020 & Emol & $\begin{array}{l}\text { Defensora de la Niñez acusa } \\
\text { «abandono» del Minsal en } \\
\text { residencias del Sename ante el } \\
\text { covid-19 }\end{array}$ & $\begin{array}{l}\text { https://www.emol.com/noticias } \\
\text { /Nacional/2020/04/07/982289/ } \\
\text { Defensora-Ninez-Sename- } \\
\text { coronavirus.html }\end{array}$ \\
\hline 28 & 07-04-2020 & $\begin{array}{l}\text { El } \\
\text { Desconcierto }\end{array}$ & $\begin{array}{l}\text { El cuidado de la infancia en } \\
\text { tiempos de COVID-19 }\end{array}$ & $\begin{array}{l}\text { https://www.eldesconcierto.cl/ } \\
\text { 2020/04/07/el-cuidado-de-la- } \\
\text { infancia-en-tiempos-de-covid- } \\
\text { 19/ }\end{array}$ \\
\hline 29 & 08-04-2020 & La Cuarta & $\begin{array}{l}\text { Joven violó la cuarentena y } \\
\text { viajó en el maletero de un taxi } \\
\text { para ver a su pololo }\end{array}$ & $\begin{array}{l}\text { https://www.lacuarta.com/mun } \\
\text { do/noticia/joven-violo-la- } \\
\text { cuarentena-taxi/481763/ }\end{array}$ \\
\hline 30 & 09-04-2020 & The Clinic & $\begin{array}{l}\text { Dos jóvenes son detenidos por } \\
\text { tercera vez tras infringir } \\
\text { cuarentena y toque de queda }\end{array}$ & $\begin{array}{l}\text { https://www.theclinic.cl/2020/ } \\
\text { 04/09/dos-jovenes-son- } \\
\text { detenidos-por-tercera-vez-tras- } \\
\text { infringir-cuarentena-y-toque- } \\
\text { de-queda/ }\end{array}$ \\
\hline 31 & 09-04-2020 & The Clinic & $\begin{array}{l}\text { Detienen por cuarta vez a } \\
\text { joven infringiendo cuarentena } \\
\text { en Chillán }\end{array}$ & $\begin{array}{l}\text { https://www.theclinic.cl/2020/ } \\
\text { 04/09/detienen-por-cuarta-vez- } \\
\text { a-joven-infringiendo- } \\
\text { cuarentena-en-chillan/ }\end{array}$ \\
\hline 32 & $10-04-2020$ & La Cuarta & $\begin{array}{l}\text { ¿Por qué el bicho atacaría con } \\
\text { menos fuerza a los más } \\
\text { peques? }\end{array}$ & $\begin{array}{l}\text { https://www.lacuarta.com/cron } \\
\text { ica/noticia/bicho-menos- } \\
\text { fuerza-mas-peques/482508/ }\end{array}$ \\
\hline 33 & $11-04-2020$ & Interferencia & $\begin{array}{l}\text { Adultos mayores: así de } \\
\text { expuesto es el grupo más } \\
\text { vulnerable a la pandemia de } \\
\text { Covid-19 }\end{array}$ & $\begin{array}{l}\text { https://interferencia.cl/articulos } \\
\text { /adultos-mayores-asi-de- } \\
\text { expuesto-es-el-grupo-mas- } \\
\text { vulnerable-la-pandemia-de- } \\
\text { covid-19 }\end{array}$ \\
\hline 34 & $12-04-2020$ & La Cuarta & $\begin{array}{l}\text { Fabiola, la víctima fatal más } \\
\text { joven del maldito virus }\end{array}$ & $\begin{array}{l}\text { https://www.lacuarta.com/cron } \\
\text { ica/noticia/fabiola-victima- } \\
\text { fatal-joven/482887/ }\end{array}$ \\
\hline 35 & $16-04-2020$ & Publimetro & $\begin{array}{l}\text { Iban a una fiesta y se les pasó } \\
\text { la hora: jóvenes fueron } \\
\text { sorprendidos violando toque de } \\
\text { queda en Las Condes. }\end{array}$ & $\begin{array}{l}\text { https://www.publimetro.cl/cl/s } \\
\text { ocial/2020/04/16/las-condes- } \\
\text { cuarentena-coronavirus- } \\
\text { jovenes-sorprendidos-autos- } \\
\text { rompiendo-toque-queda.html }\end{array}$ \\
\hline 36 & $16-04-2020$ & La Tercera & $\begin{array}{l}\text { Gobierno interpone denuncia } \\
\text { contra jóvenes que fueron } \\
\text { sorprendidos en Las Condes } \\
\text { transgrediendo toque de queda }\end{array}$ & $\begin{array}{l}\text { https://www.latercera.com/naci } \\
\text { onal/noticia/gobierno- } \\
\text { interpone-denuncia-contra- } \\
\text { jovenes-que-fueron- } \\
\text { sorprendidos-en-las-condes- } \\
\text { transgrediendo-toque-de- } \\
\text { queda/2JKKNBQFJFFODBTO } \\
\text { RRBNDWTOWE/ }\end{array}$ \\
\hline 37 & $18-04-2020$ & $\begin{array}{l}\text { El } \\
\text { Ciudadano }\end{array}$ & $\begin{array}{l}\text { Temuco: INDH presentará } \\
\text { querella contra militares que } \\
\text { agredieron a un joven durante } \\
\text { el toque de queda }\end{array}$ & $\begin{array}{l}\text { https://www.elciudadano.com/ } \\
\text { chile/temuco-indh-presentara- } \\
\text { querella-contra-militares-que- } \\
\text { agredieron-a-un-joven-durante- }\end{array}$ \\
\hline
\end{tabular}




\begin{tabular}{|c|c|c|c|c|}
\hline & & & & el-toque-de-queda/04/18/ \\
\hline 38 & $19-04-2020$ & $\begin{array}{l}\text { El } \\
\text { Ciudadano }\end{array}$ & $\begin{array}{l}\text { Fech lanza campaña para llevar } \\
\text { insumos sanitarios y alimentos } \\
\text { a familias y mujeres privadas } \\
\text { de libertad }\end{array}$ & $\begin{array}{l}\text { https://www.elciudadano.com/ } \\
\text { chile/fech-lanza-campana- } \\
\text { para-llevar-insumos-sanitarios- } \\
\text { y-alimentos-a-familias-y- } \\
\text { mujeres-privadas-de- } \\
\text { libertad/04/19/ }\end{array}$ \\
\hline 39 & 21-04-2020 & $\begin{array}{l}\text { El } \\
\text { Ciudadano }\end{array}$ & $\begin{array}{l}\text { Hambre, pobreza y muerte: el } \\
\text { peligro de los niños ante el } \\
\text { coronavirus }\end{array}$ & $\begin{array}{l}\text { https://www.elciudadano.com/r } \\
\text { eportaje-destacado-mejor- } \\
\text { periodismo/hambre-pobreza- } \\
\text { muerte-el-peligro-de-los-ninos- } \\
\text { ante-el-coronavirus/04/21/ }\end{array}$ \\
\hline 40 & 21-04-2020 & $\begin{array}{l}\text { El } \\
\text { Ciudadano }\end{array}$ & $\begin{array}{l}\text { Rancagua: muere joven de } 26 \\
\text { años por COVID-19 }\end{array}$ & $\begin{array}{l}\text { https://www.elciudadano.com/ } \\
\text { chile/rancagua-muere-joven- } \\
\text { de-26-anos-por-covid- } \\
\text { 19/04/21/ }\end{array}$ \\
\hline 41 & 21-04-2020 & Cooperativa & $\begin{array}{l}\text { Joven de } 26 \text { años es el primer } \\
\text { fallecido a causa del Covid-19 } \\
\text { en O’Higgins }\end{array}$ & $\begin{array}{l}\text { https://www.cooperativa.cl/not } \\
\text { icias/sociedad/salud/coronaviru } \\
\text { s/joven-de-26-anos-es-el- } \\
\text { primer-fallecido-a-causa-del- } \\
\text { covid-19-en-o-higgins/2020- } \\
\text { 04-21/113420.html }\end{array}$ \\
\hline 42 & $25-04-2020$ & La Tercera & $\begin{array}{l}\text { Encuesta de Desarrollo Social } \\
\text { a jóvenes entre } 14 \text { y } 24 \text { años: } \\
40 \% \text { piensa que los adultos } \\
\text { «exageran» con el coronavirus }\end{array}$ & $\begin{array}{l}\text { https://www.latercera.com/naci } \\
\text { onal/noticia/encuesta-de- } \\
\text { desarrollo-social-a-jovenes- } \\
\text { entre-14-y-24-anos-40-piensa- } \\
\text { que-los-adultos-exageran-con- } \\
\text { el- } \\
\text { coronavirus/YEJGVGDDTJB } \\
\text { WXMKPRC3IR4WBOM/ }\end{array}$ \\
\hline 43 & $25-04-2020$ & El Dínamo & $\begin{array}{l}\text { Encuesta revela que } 1 \text { de cada } \\
3 \text { jóvenes cree que no se } \\
\text { contagiará de Covid-19. }\end{array}$ & $\begin{array}{l}\text { https://www.eldinamo.cl/nacio } \\
\text { nal/2020/04/25/encuesta- } \\
\text { revela-que-1-de-cada-3- } \\
\text { jovenes-cree-que-no-se- } \\
\text { contagiara-de-covid-19/ }\end{array}$ \\
\hline 44 & $26-04-2020$ & $\mathrm{CNN}$ & $\begin{array}{l}\text { Subsecretaria de la Niñez } \\
\text { analiza encuesta a jóvenes } \\
\text { sobre el coronavirus: «No le } \\
\text { temen a perder el año escolar» }\end{array}$ & $\begin{array}{l}\text { https://www.cnnchile.com/lodi } \\
\text { jeronencnn/subsecretaria-de-la- } \\
\text { ninez-encuesta-jovenes- } \\
\text { coronavirus-perder-ano- } \\
\text { escolar_20200426/ }\end{array}$ \\
\hline 45 & 28-04-2020 & $\begin{array}{l}\text { Ministerio } \\
\text { de } \\
\text { Desarrollo } \\
\text { Social }\end{array}$ & $\begin{array}{l}\text { Encuesta del Ministerio de } \\
\text { Desarrollo Social y Familia } \\
\text { alerta que uno de cada tres } \\
\text { jóvenes cree que no se } \\
\text { contagiará de Covid-19 }\end{array}$ & $\begin{array}{l}\text { http://www.desarrollosocialyfa } \\
\text { milia.gob.cl/noticias/encuesta- } \\
\text { del-ministerio-de-desarrollo- } \\
\text { social-y-familia-alerta-que- } \\
\text { uno-de-cada-tres-jovenes-cree- } \\
\text { que- }\end{array}$ \\
\hline 46 & $28-04-2020$ & La Tercera & $\begin{array}{l}\text { La desconocida enfermedad } \\
\text { inflamatoria vinculada al } \\
\text { Covid-19 que afecta a niños y }\end{array}$ & $\begin{array}{l}\text { https://www.latercera.com/que } \\
\text {-pasa/noticia/la-desconocida- } \\
\text { enfermedad-inflamatoria- }\end{array}$ \\
\hline
\end{tabular}




\begin{tabular}{|c|c|c|c|c|}
\hline & & & alerta a los médicos & \begin{tabular}{|l|} 
vinculada-al-covid-19-que- \\
afecta-a-ninos-y-alerta-a-los- \\
medicos/4SFFLP2U6BEGZED \\
SC7JWNH6YZE/
\end{tabular} \\
\hline 47 & $30-04-2020$ & La Tercera & $\begin{array}{l}\text { El alto precio que pagan los } \\
\text { adultos mayores en cuarentena: } \\
\text { pierden la noción del tiempo y } \\
\text { la habilidad de hablar }\end{array}$ & $\begin{array}{l}\text { https://www.latercera.com/que } \\
\text {-pasa/noticia/el-alto-precio- } \\
\text { que-pagan-los-adultos- } \\
\text { mayores-en-cuarentena- } \\
\text { pierden-la-nocion-del-tiempo- } \\
\text { y-la-habilidad-de- } \\
\text { hablar/X2AKYQOU2VE2HM } \\
\text { CF6OKXGULBHQ/ }\end{array}$ \\
\hline 48 & $30-04-2020$ & La Cuarta & $\begin{array}{l}\text { Aldeas Infantiles SOS lanza } \\
\text { campaña para apoyar a los } \\
\text { niños en medio del Covid-19 }\end{array}$ & $\begin{array}{l}\text { https://www.lacuarta.com/cron } \\
\text { ica/noticia/aldeas-infantiles- } \\
\text { sos-lanza-campana-apoyar-los- } \\
\text { ninos-medio-del-covid- } \\
\text { 19/490243/ }\end{array}$ \\
\hline 49 & $03-05-2020$ & La Cuarta & $\begin{array}{l}\text { «Se creen invencibles»: } \\
\text { gobierno condena } \\
\text { multitudinaria fiesta } \\
\text { clandestina en Maipú }\end{array}$ & $\begin{array}{l}\text { https://www.lacuarta.com/cron } \\
\text { ica/noticia/gobierno-condena- } \\
\text { fiesta-clandestina/490912/ }\end{array}$ \\
\hline 50 & $03-05-2020$ & $\begin{array}{l}\text { El } \\
\text { Ciudadano }\end{array}$ & $\begin{array}{l}\text { Jóvenes chilenos varados en } \\
\text { isla de Honduras fabricaron } \\
\text { una caña de pescar para poder } \\
\text { comer: Consulado aún no se } \\
\text { pronuncia }\end{array}$ & $\begin{array}{l}\text { https://www.elciudadano.com/ } \\
\text { chile/jovenes-chilenos- } \\
\text { varados-en-isla-de-honduras- } \\
\text { fabricaron-una-cana-de-pescar- } \\
\text { para-poder-comer-consulado- } \\
\text { aun-no-se-pronuncia/05/03/ }\end{array}$ \\
\hline 51 & $03-05-2020$ & $\begin{array}{l}\text { La Voz de } \\
\text { Maipú }\end{array}$ & $\begin{array}{l}\text { [VIDEO] Jóvenes maipucinos } \\
\text { realizaron masiva fiesta } \\
\text { electrónica en el día con más } \\
\text { contagios por COVID-19 en } \\
\text { Chile }\end{array}$ & $\begin{array}{l}\text { https://lavozdemaipu.cl/video- } \\
\text { jovenes-maipucinos- } \\
\text { realizaron-masiva-fiesta- } \\
\text { electronica-en-el-dia-con-mas- } \\
\text { contagios-por-covid-19-en- } \\
\text { chile/ }\end{array}$ \\
\hline 52 & 04-05-2020 & La Tercera & $\begin{array}{l}\text { Promesas en reconstrucción: } \\
\text { cómo afecta el coronavirus a } \\
\text { los más jóvenes }\end{array}$ & $\begin{array}{l}\text { https://www.latercera.com/el- } \\
\text { deportivo/noticia/promesas-en- } \\
\text { reconstruccion-como-afecta-el- } \\
\text { coronavirus-a-los-mas- } \\
\text { jovenes/DOM3TCH4SJEJRJC } \\
\text { NNNOMYWH7PE/ }\end{array}$ \\
\hline 53 & $04-05-2020$ & El Mostrador & $\begin{array}{l}\text { COVID-19 en Argentina: } \\
\text { joven contagió y causó la } \\
\text { muerte de su abuelo tras haber } \\
\text { asistido a una fiesta vulnerando } \\
\text { la cuarentena }\end{array}$ & $\begin{array}{l}\text { elmostrador.cl/noticias/2020/0 } \\
\text { 5/04/covid-19-en-argentina- } \\
\text { joven-contagio-y-causo-la- } \\
\text { muerte-de-su-abuelo-tras- } \\
\text { haber-asistido-a-una-fiesta- } \\
\text { vulnerando-la-cuarentena/ }\end{array}$ \\
\hline 54 & 04-05-2020 & El Mostrador & $\begin{array}{l}\text { Contagios en residencias para } \\
\text { adultos mayores, la } \\
\text { vulnerabilidad de Chile a cara } \\
\text { descubierta }\end{array}$ & $\begin{array}{l}\text { https://www.elmostrador.cl/not } \\
\text { icias/pais/2020/05/04/contagio } \\
\text { s-en-residencias-para-adultos- } \\
\text { mayores-la-vulnerabilidad-de- } \\
\text { chile-a-cara-descubierta/ }\end{array}$ \\
\hline
\end{tabular}




\begin{tabular}{|c|c|c|c|c|}
\hline 55 & 04-05-2020 & \begin{tabular}{|l} 
Bío-Bío \\
Chile
\end{tabular} & $\begin{array}{l}\text { Figueroa seguirá adelante con } \\
\text { retorno a clases y Colegio de } \\
\text { Profesores evitará regreso } \\
\text { durante mayo }\end{array}$ & $\begin{array}{l}\text { https://www.biobiochile.cl/noti } \\
\text { cias/nacional/chile/2020/05/04/ } \\
\text { figueroa-seguira-retorno- } \\
\text { colegio-profesores-evitara- } \\
\text { regreso-clases-mayo.shtml }\end{array}$ \\
\hline 56 & 04-05-2020 & La Tercera & $\begin{array}{l}\text { Por favor, que ya suene la } \\
\text { campana }\end{array}$ & $\begin{array}{l}\text { https://www.latercera.com/opi } \\
\text { nion/noticia/por-favor-que-ya- } \\
\text { suene-la- } \\
\text { campana/VW2G74X3N5HPJF } \\
\text { KXKF3TAEW754/ }\end{array}$ \\
\hline 57 & 05-05-2020 & El Mostrador & $\begin{array}{l}\text { Niñez y Pandemia: un asunto } \\
\text { social }\end{array}$ & $\begin{array}{l}\text { https://www.elmostrador.cl/age } \\
\text { nda-pais/2020/05/05/ninez-y- } \\
\text { pandemia-un-asunto-social/ }\end{array}$ \\
\hline 58 & 08-05-2020 & The Clinic & $\begin{array}{l}\text { Para ser inmunes: Así son las } \\
\text { fiestas de los jóvenes de } \\
\text { Estados Unidos para } \\
\text { contagiarse el Covid-19 }\end{array}$ & $\begin{array}{l}\text { https://www.elciudadano.com/r } \\
\text { eportaje-destacado-mejor- } \\
\text { periodismo/para-ser-inmunes- } \\
\text { asi-son-las-fiestas-de-los- } \\
\text { jovenes-de-estados-unidos- } \\
\text { para-contagiarse-el-covid- } \\
\text { 19/05/08/ }\end{array}$ \\
\hline 59 & 08-05-2020 & \begin{tabular}{|l|} 
El \\
Ciudadano
\end{tabular} & $\begin{array}{l}\text { Para ser inmunes: Así son las } \\
\text { fiestas de los jóvenes de } \\
\text { Estados Unidos para } \\
\text { contagiarse el Covid-19 }\end{array}$ & $\begin{array}{l}\text { https://www.elciudadano.com/r } \\
\text { eportaje-destacado-mejor- } \\
\text { periodismo/para-ser-inmunes- } \\
\text { asi-son-las-fiestas-de-los- } \\
\text { jovenes-de-estados-unidos- } \\
\text { para-contagiarse-el-covid- } \\
\text { 19/05/08/ }\end{array}$ \\
\hline 60 & $11-05-20$ & The Clinic & $\begin{array}{l}\text { La cuarentena de los adultos } \\
\text { mayores que viven solos }\end{array}$ & $\begin{array}{l}\text { https://www.theclinic.cl/2020/ } \\
\text { 05/11/la-cuarentena-de-los- } \\
\text { adultos-mayores-que-viven- } \\
\text { solos/ }\end{array}$ \\
\hline 61 & $12-05-20$ & La Cuarta & $\begin{array}{l}\text { «Habrá que agarrarlos a } \\
\text { peñascazos»: la dura amenaza } \\
\text { de alcaldesa a jóvenes que } \\
\text { hacen fiestas }\end{array}$ & $\begin{array}{l}\text { https://www.lacuarta.com/cron } \\
\text { ica/noticia/alcaldesa-contagios- } \\
\text { fiestas/495261/ }\end{array}$ \\
\hline
\end{tabular}

